\title{
ENERGY EFFICIENCY IN RAILWAYS: ENERGY STORAGE AND ELECTRIC GENERATION IN DIESEL ELECTRIC LOCOMOTIVES
}

\author{
Elena AGENJOS \\ U.P. Cartagena - Spain \\ elenaagenjos@msn.com \\ Sergio VALERO \\ U. Miguel Hernández - Spain \\ svalero@umh.es
}

\author{
Antonio GABALDÓN \\ U.P. Cartagena - Spain \\ antonio.gabaldon@upct.es \\ Mario ORTIZ \\ U. Miguel Hernández - Spain \\ mortiz@umh.es
}

\author{
U.P. Cartagena - Spain \\ Rafael J.GABALDÓN \\ ADIF - Spain \\ rgabaldon@adif.es
}

Francisco G. FRANCO, Roque MOLINA

fjgfco@gmail.com, roque.molina@upct.es

\begin{abstract}
Diesel-electric traction is a well known and established technology for railways operators, but this alternative has a considerable uncerainty for the future because electric traction has a considerable superiority. Besides, dieselelectric engines waste energy when resistivebraking is used. This non-regenerative braking decreases the overall efficiency by 10-20\%. With these premises it is important to develop new strategies to increase the energy efficiency of diesel-electric haulag.. To reach a better efficiency, a locomotive with energy storage (battery, super-capacitors) is theoretically proposed. Besides, the possibility of using a lower thermal engine (from other diesel locomotives out of use) with energy storage devices is considered too. This solution reduces diesel consumption and $\mathrm{CO}_{2}$ emissions while being economically viable. It supposes an efficient energy management because the diesel-electric locomotive could acts as a dispersed mobile generation (DMG) unit when working under electric overhead lines, and it can be used as a distributed resource for this specific electric power system.
\end{abstract}

\section{INTRODUCTION}

Increasing energy costs have become a serious concern in our societies and consequently in railway systems. Reducing the energy consumption and improve energy efficiency are important objectives to European Union railway system operators. The opportunities for energy efficiency in railways haulage are: driving strategy (style and coasting), energy storage (in vehicles or off board) and timetables and energy/speed trade offs. Specifically, dieselelectric trains have serious disadvantages face to electric haulage: diesels can pack less horsepower on a given volume, have a greater maintenance cost (due to diesel engine), lower availability (perhaps about 10\%-15\% less than electric locomotives) lifetime, modularity, etc. This propulsion is mainly chosen for peripheral areas of transport, where the number of passengers and tonnes of goods are quite limited, and the cost of installing catenary and electric power supplies is too high with respect to traffic needs. The use of diesel is quite limited in EU countries and electric traction should get more and more importance in next decades. Due to these facts diesel locomotives are in excess in some countries and used at a minimum level (maintenance in high speed lines, secondary lines,..). In electrified lines, coasting and regenerative braking policies were introduced some decades ago to reduce energy consumption. Regenerative braking is only effective if other trains are available to use the regenerated energy. Successful implementation of regenerative braking requires the use of resistor banks to remove excess energy or inverting substations to regenerate onto the local distribution network, but these possibilities can not be achieved by diesel-electric haulage.
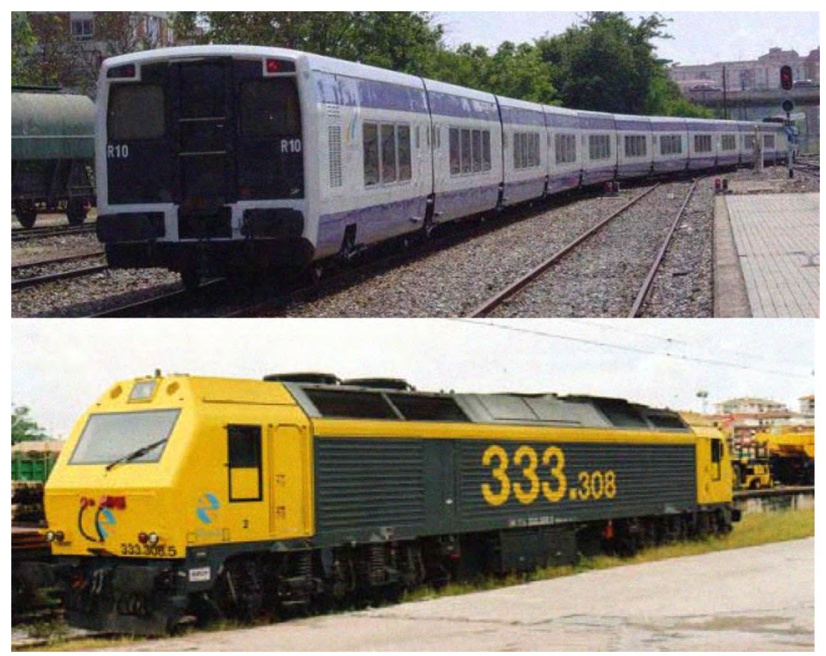

Figure 1. Talgo IV coaches and diesel-electric locomotive used for haulage.

Fortunately, recent developments in energy storage devices, particularly supercapacitors and flywheels [1], [2] have made energy storage a viable alternative to apply to railway systems and specifically for diesel-electric units. Energy storage devices can be used to improve energy efficiency by storing regenerated energy from conventional resistive braking. This paper explores the possibilities and use of energy storage in diesel-electric systems, using a real intercity passenger train "Altaria" as a case study (Altaria trains are Talgo IV coaches series unit with diesel-electric 
or electric traction units, used in medium speed tracks - see figure 1 , i.e. up to $180 \mathrm{~km} / \mathrm{h}$ of maximum speed. In our case, only diesel-electric traction is used).

\section{ENERGY STORAGE IN RAILWAYS}

Supercapacitors (SC), flywheels and Supermagnetics Energy Storage (SMES) are new components that can be used for short-duration energy storage [3],[4]. For example, the University of Texas at Austin Center for Electromechanics (UT-CEM) is currently developing an Advanced Locomotive Propulsion System (ALPS) based on flywheels as part of theNext Generation High-Speed Rail program sponsored by the Federal Railroad Administration (FRA) [5] but flywheels are now an expensive alternative for existing diesel-electric locomotives. Indeed is it well known that SMES are under development and are very expensive devices. French railways (SNCF) develops other hybrid-locomotive platform based on an old switcher locomotive (class BB63000) with fuel-cell, SC, batteries, and flywheels [6].

On the contrary, Supercapacitors are a viable alternative from economical and technical viewpoints. The advantages of these components are: the stored energy density $(\mathrm{Wh} / \mathrm{kg})$ and the volume. The currently available supercapcitors are up to some kilo-Farads (for example, Maxwell Technologies) and their volume is quite reduced.

In comparison to standard batteries, the energy density of supercapacitors is lower by an average factor of 10 . However, their energy density is compatible with a large range of power applications that need high instantaneous power during short periods of time.

The above characteristics of power demand are typically found in transportation systems, and specifically in dieselelectric haulage. Perhaps the main advantage in the use of supercapacitors in comparison with batteries is their life time and the number of cycles of storage. Table I presents the main characteristics of supercapacitor and battery energy storage systems.

Table I. Characteristics of batterys and SC

\begin{tabular}{|l|c|c|}
\hline Parameter & Battery & SC \\
\hline Energy $(\mathrm{Wh} / \mathrm{kg})$ & $10-600$ & $1-10$ \\
\hline Number of cycles & 1000 & 500000 \\
\hline
\end{tabular}

The objective of this paper is to present how supercapacitive and battery storage can be used for increasing the energy efficiency in a diesel-electric railway system and helping in this way in the use of diesel-electric traction in secondary itineraries. Two different solutions will be presented to reach that goal: recovery of braking energy, and storage with changes in the diesel engine size and uses.

\section{CASE STUDY: THE ITINERARY}

In order to compare the standard diesel-electric unit (Altaria) to the proposed solutions, and also with the objective of dimensioning the main elements (storage, diesel engine, etc), a typical itinerary was selected: MadridCartagena. It is situated in the southeast of Spain. Specifically this itinerary has an electrified overhead system ( $3 \mathrm{kV}, \mathrm{CC}$ with two-track catenary) from Madrid to Albacete (around $300 \mathrm{~km}$ ) and a non electrified one from Albacete to Cartagena (single track, $250 \mathrm{~km}$ ) without change of the diesel locomotive. There are six trains on weekdays. Some of these trains have diesel-hydraulic traction (40\%) and the rest uses diesel-electric traction. The results presented will only be valid for the chosen itinerary (Albacete-Cartagena) and it was selected due to their not fat profile that conditions the size of the storage and engine (i.e., energy constraints on the diesel motors are higher, in comparison to a flat line, due to the considerable acceleration power needed to overcome grade resistence and also to the high braking power recovery during down-hills). Obviously, the same simulation method developed here can be applied to analyze other railway lines.

The altitude curve of the typical itinerary (altitude versus time) is given in Fig. 2.

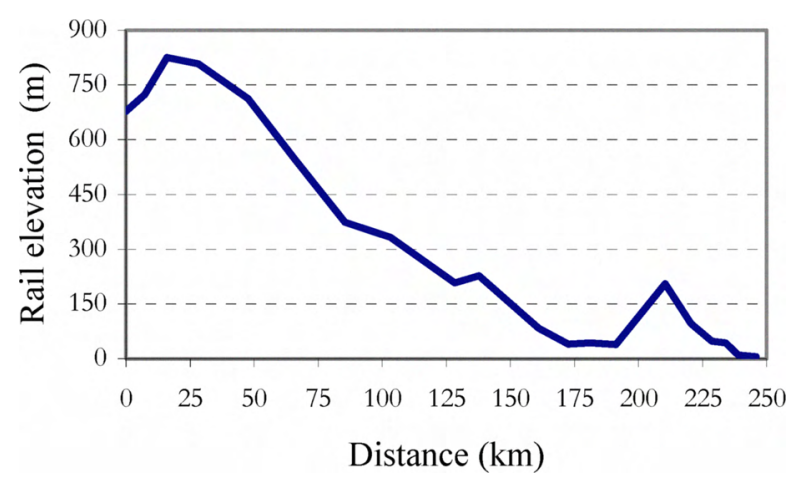

Figure 2. Albacete-Cartagena (sea level) line profile

This itinerary corresponds to a line that is actually being renovated (2008) with rebuilt medium-speed diesel-electric locomotives (up to $200 \mathrm{~km} / \mathrm{h}$ based in the Renfe series 333.X, used in this work for simulation purposes, series that is very closed to GEC Class 67 developed for UK operators).

The chosen trains were built by Patentes Talgo, Spain (coaches) and Alsthom-Macosa, Spain (locomotives JT26TW licensed by General Motors), whose main characteristics are [7], [8]:

- Locomotive bogies disposition: CoCo

- Total weight: $120 \mathrm{t}$

- Diesel engine power: $2237 \mathrm{~kW}$ (UIC)

- Maximum tractive effort $(20 \mathrm{~km} / \mathrm{h}): 32 \mathrm{kN}$

- Max. speed: 120-146 km/h (depending of subseries).

- Talgo IV coaches: 118 ton (9 coaches) 


\section{BASIC TRAIN SIMULATOR}

To evaluate the storage needs and the power and energy demand of the train in the itinerary, an specific program was developed in the Universidad Politécnica de Cartagena (Spain) using MATLAB tools. The acceleration, a, of a train (i.e., forces opposed to the movement that must be overcomed by the tractive effort, see figure 3 ) is done by equation:

Mass $* a=($ Traction - Resistive forces \pm Grade $)[1]$

Traction

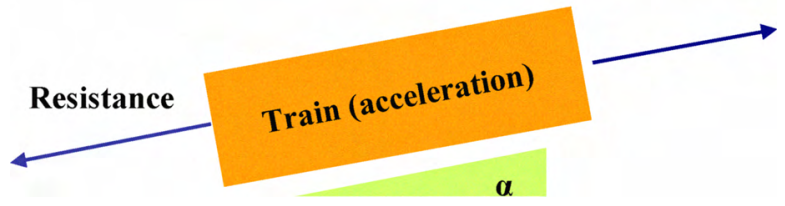

Figure 3. Gross resistance and traction forces

The resistance is the sum of all resistive forces acting on the train at a given time or place. Much use is made of unit resistance measured in $\mathrm{kN}$ per ton of train weight (locomotive, coaches, wagons). The resistance forces are examined in detail in with different models [9],[10] but they are not the objective of this paper. The main forces simulated in our software are:

- Internal resistance of the locomotive.

- Journal friction (rolling and track resistances).

- Flange resistance (proportional with the speed)

- Air resistance (proportional with the square of the speed).

- Resistance of external loads (lighting, HVAC, ..).

- Curve resistance.

- $\quad$ Starting resistance (inertia).

- Grade resistance (the main actor for energy storage).

The value of theses forces is implemented in the simulation package and some examples are shown in figures 4 and 5 . Worthy of note is that some forces are a function of speed and so these calculations are an iterative process (force, acceleration, speed, and finally the overall force).

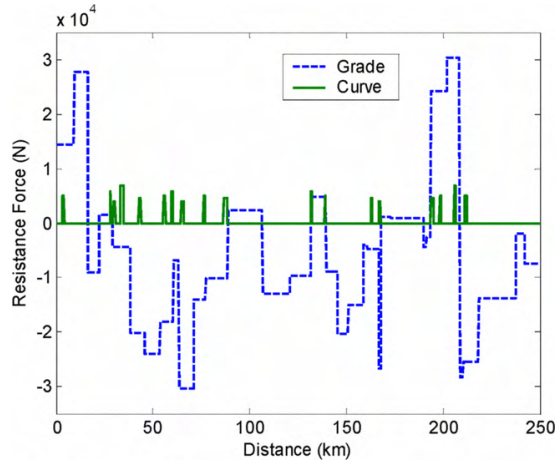

Figure 4. Curve and Grade forces in the itinerary

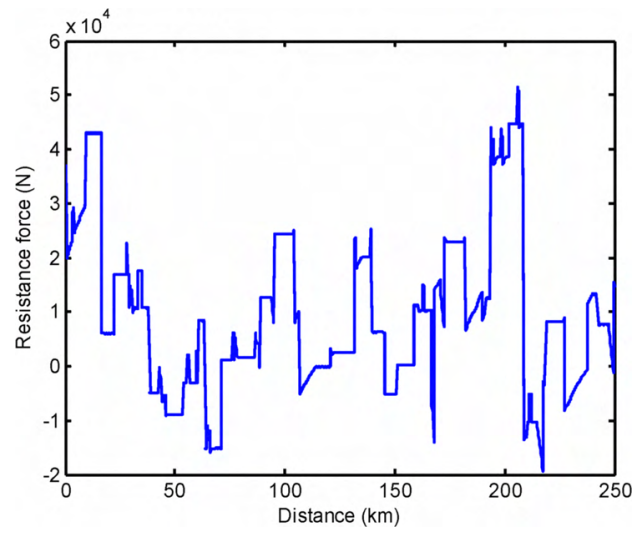

Figure 5. Overall resistive force

These forces must be overcomed by a pulling force known as tractive force or effort, and it is a function of each diesellocomototive horsepower (diesel engine, electrical coupling, generator, $\mathrm{AC} / \mathrm{DC}$ drives and electrical motors). The most important characteristic is the tractive effort curve (but other electrical and mechanical characteristics, for example efficiency, adhesion,..., were taken into account in our simulator). An example of this effort (for the rebuilt locomotive Vossloh class 334, ex GEC-Alsthom series 333) is shown in figure 6 for an specific position of the throttle. Tractive Effort - Speed Curve
61:27 Gear Ratio $-965.2 \mathrm{~mm}$ Wheels 61:27 Gear Ratio - $966.2 \mathrm{~mm}$ Wheels
UIC Conditions - $300 \mathrm{~kW}$ HEP Load

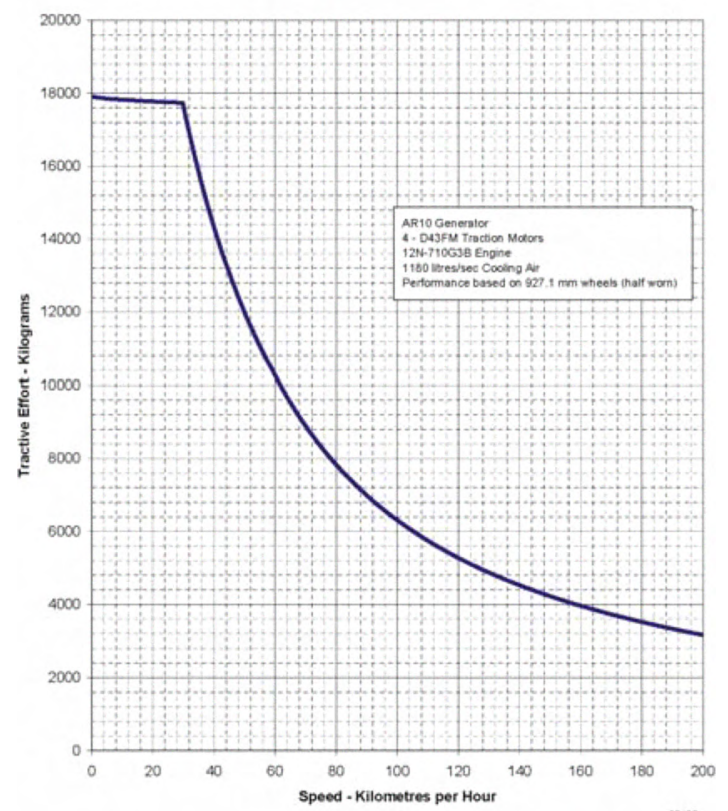

Figure 6. Tractive effort-speed curve. Diesel-electric locomotive Vossloh series 334.

The results for equation [1] taking into account the corrected mass (mass+rotating mass effects correction) are shown in figure 7 . 


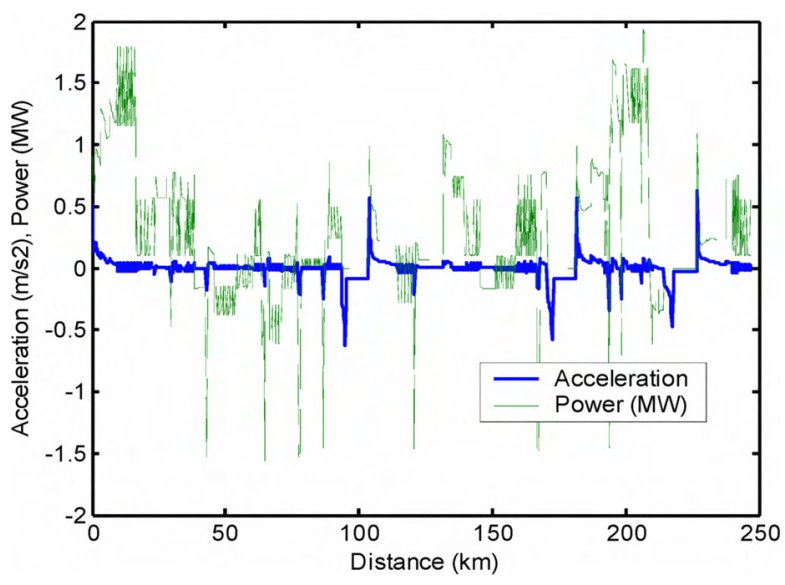

Figure 7. Train acceleration and power demand

\section{DYNAMIC BRAKING AND STORAGE}

From figure 7 , it can be seen that the train has negative acceleration (braking) throughout the itinerary $(250 \mathrm{~km}$ in our case), and the train needs some power peaks to overcome starting forces after train stops (see peaks of 0,6 $\mathrm{m} / \mathrm{s}^{2}$ around points 120,180 and 220 ). This negative acceleration id achieved through braking. Electrical locomotives have regenerative braking (the traction motor works as a generator) through the catenary, but diesel units have dynamic braking (the power supplied by motors are used to feed roof resistors cooled with forced ventilation), a non efficient use of energy The dynamic brake effort curve for a position ( 8 positions are possible to manage braking effort) is shown in figure 8 for the series Vossloh 334 and GEC-Alsthom series 333.X

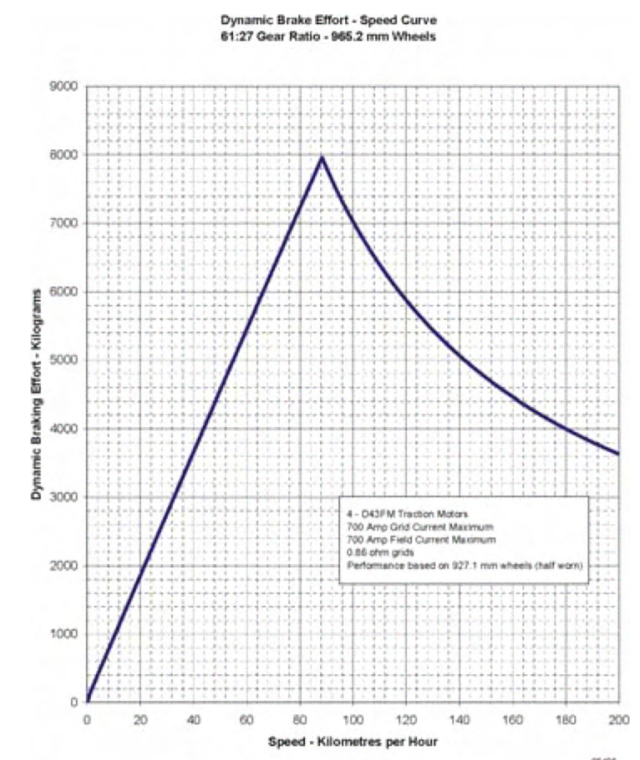

Figure 9. Dynamic braking effort curve

This dynamic braking represents the second main "losses generator" for a diesel locomotive. Of course, additional losses are due to conventional mechanical brakes, but the main braking effort is achieved with resistor, and this energy is converted in heat. The idea proposed in the paper and used in some prototypes (Plathée, France [6], Japan, USA [5]) is to recover and store braking energy. In the next paragraph this possibility for Spanish diesel-electrical locomotives still in use will be evaluated to improve their operative life and efficiency.

The energy balance is shown in Figure 10. The energy will be stored using electronic converters in some storage medium (Batteries, CS, flywheels,...). To reduce costs, the resistive breaking is not removed and in this way it could be used for emergency, if storage capacity fails or the storage is full. When the train starts, the energy stored can feed the traction motors and help the locomotive to reach the necessary traction effort with a less use of the diesel engine. Energy levels up to $500 \mathrm{MJ} /$ itinerary can be recovered for this real example according to acceleration (see figure 7).

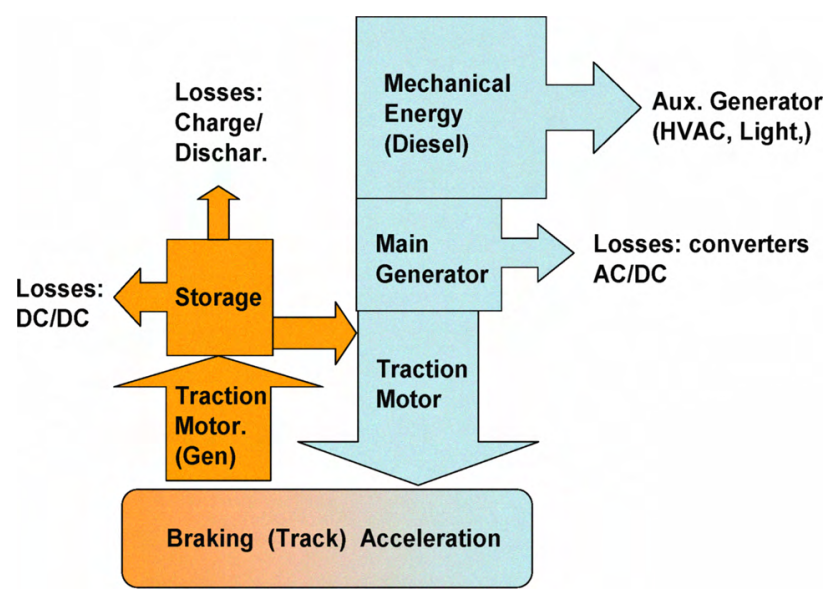

Figure 10. Energy balance: braking and throttle.

\section{SIZING OF STORAGE RESERVOIR}

Regarding the design of storage elements, several properties should be taken into account. As the first purpose is to recovery energy during braking, the stored energy is the main criteria, but the storage system has to be power compatible to the energy needs for railway traction application (train stops, speed limitations, start up). Also, a high efficiency during charges and discharges is desirable. Finally the storage device should be cost effective and our loco should have the necessary volume to introduce storage and electronic devices (this aspect sometimes is neglected, but is an important restriction in manycases). Two cases have been considered for this simulation:

a) Simple storage: The peak power that the storage should assume must correspond to the maximum energy recovery in braking processes (taking into account losses in converters and storage).

b) Storage and change of he diesel engine: The loco will use a diesel motor unit (from other diesel locomotive) with less HP, but working at a higher efficiency level. The energy storage system is 
considered as an energy buffer, dedicated for smoothing power constraints on the resized diesel engine.

For each alternative two technologies are considered: batteries and supercapacitors. Flywheels are other interesting option, but prices are difficult to be obtained from suppliers, and flywheel need accurate mechanical maintenance [4]. The main problem of batteries is their lifetime (the number of cycles is strongly reduced compared to the general lifetime of locomotives, about $40-50$ years), but the price is their main advantage. Some new technologies (gel and sulphur batteries) will be evaluated face to SC.

\section{Simple storage}

The negative values in figure 7 represent a percent of the energy that should be stored. Numerical integration of energy curve gives the amount of energy that should be managed by capacitive or battery storage. To evaluate this energy we performed an iterative process taking into account the areas with generation and power demand, i.e. the locomotive stores for some minutes, demands energy and then it stores again. When the energy stored in each fraction of the iterary is completely used by the six traction motors, the program saves the new value and resets the storage capacity (see figure 11). The maximum of the values in the itinerary (Cartagena-Albacete-Cartagena) is the size needed for the reservoir of storage.

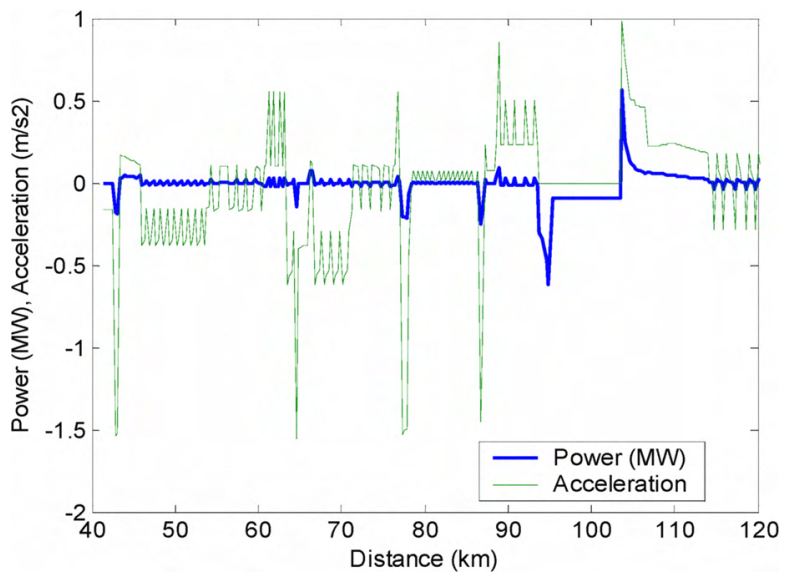

Figure 11. Storage sizing (first train stop)

For instance, in figure 11, it can be shown that the loco alternatively supplies and demands power, until the train gets the first stop from Albacete. In this point ( $\mathrm{km} \mathrm{105),} \mathrm{the}$ train need an energy surplus to overcome the starting forces and empties the reservoir of energy. The integral of the power curve in this area gives us the storage size (in this case about $85 \mathrm{MJ}$ )

\section{Change of diesel engine}

Another possibility for this study, is to use the diesel engine of other locomotive. Again, a GEC-Alsthom locomotive (series 319) with a rated power of $1900 \mathrm{HP}$ (face to 3000 HP of 333.X series). This alternative reduces fuel consumption, locomotive weight and increases available volume for storage. Obviously, other possibility is to use directly the series 319 locomotive. Notice that $1900 \mathrm{HP}$ (around 1.4 MW) are insufficient to accelerate the train, see figure 7 , and to satisfy the timetable assigned to the train. The procedure is the following: the needed power profile (figure 7) is shared into an averaged value and a fluctuating one. The average power gives us the mean state of diesel engine during the itinerary $(300 \mathrm{~kW})$ and the fluctuating power represents so the needs for acceleration and braking. The integration of this part provides the amount of energy that should be managed by the reservoir of storage (580 MJ to accelerate, $720 \mathrm{MJ}$ from braking plus the constant energy supplied by diesel. These quantities are over the range forecasted by ALPS project in the USA [6], and additional space -perhaps a tender-wagon- to store the reservoir is needed). The acceleration of the train needs some additional supply from the diesel power engine (up to $1100 \mathrm{~kW}$ ) and the energy stored in the reservoir. This is the possibility analyzed in a previous work by Barrade [11].These results correspond with figure 12 .

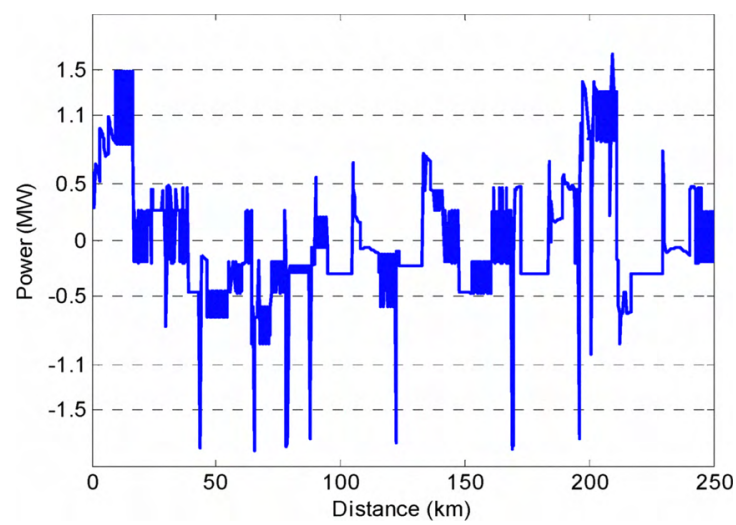

Figure 12.Fluctuating power demand (base $300 \mathrm{~kW}$ )

\section{RESULTS: IMPROVEMENT IN EFFICENCY}

Two possibilities have been evaluated: SC and batteries. The batteries considered are lead acid, $\mathrm{NiCd}$, and gel technologies from the manufacturer SEC Industrial Battery, (UK). The supercapacitors chosen for that application were BCAXX form Maxwell Technologies, USA.

Nominal capacitance of SC ranges from 650 to 3000 Farads and the maximum voltage is 2.5 Volts. The main characteristics are given in Tables II and III.

Table II. Battery characteristics

\begin{tabular}{|l|c|c|c|c|}
\hline Battery & $\begin{array}{c}\text { Energy } \\
(\mathbf{k W h} / \mathbf{k g})\end{array}$ & $\begin{array}{c}\text { Mass } \\
(\mathbf{k g})\end{array}$ & $\begin{array}{c}\text { Volume } \\
\left(\mathbf{m}^{\mathbf{3}}\right)\end{array}$ & $\begin{array}{c}\text { Cost } \\
(\boldsymbol{\epsilon} / \mathbf{k W h})\end{array}$ \\
\hline 2 CMT 4500 & 5956 & 288 & 0.082 & 125 \\
\hline 12 TLG 250 & 268,2 & 63,3 & 0.028 & 400 \\
\hline KL 1500P & 607.2 & 80.6 & 0.032 & 1900 \\
\hline
\end{tabular}


Table III. SC characteristics

\begin{tabular}{|l|c|c|c|c|}
\hline Capacitor & $\begin{array}{c}\text { Energy } \\
(\mathbf{k W h} / \mathbf{k g})\end{array}$ & $\begin{array}{c}\text { Mass } \\
(\mathbf{k g})\end{array}$ & $\begin{array}{c}\text { Volume } \\
\left(\mathbf{m}^{\mathbf{3}}\right)\end{array}$ & $\begin{array}{c}\text { Cost } \\
(\mathbf{\$} / \mathbf{k W h})\end{array}$ \\
\hline BCAP 1500 & 4.75 & 0.32 & 0.325 & 59.8 \\
\hline BCAP 3000 & 5.52 & 0.55 & 0.475 & 63 \\
\hline
\end{tabular}

The evaluation of the simple storage case gives us a storage level of $85 \mathrm{MJ}$. The cost and volume, for the batteries and SC selected, are shown in table IV.

Table IV. Cost of storage alternatives

\begin{tabular}{|l|c|c|c|c|}
\hline Option & $\begin{array}{c}\text { Maintenanc } \\
\mathbf{e}\end{array}$ & $\begin{array}{c}\text { Lifetim } \\
\mathbf{e} \\
\text { (years) }\end{array}$ & $\begin{array}{c}\text { Volume } \\
\mathbf{( m 3 )}\end{array}$ & $\begin{array}{c}\text { Cost } \\
\mathbf{( k € )}\end{array}$ \\
\hline 2CMT 4500 & Yes & 3 & 1,7 & 63 \\
\hline 12 TLG 250 & No & 6 & 12,6 & 100 \\
\hline KL 1500P & Yes & 20 & 1,5 & 42 \\
\hline BCAP 3000 & No & 20 & 3,8 & 550 \\
\hline
\end{tabular}

All the options are viable except the gel battery 12TLG250 because the volume available in the locomotive for storage and converters is $6 \mathrm{~m}^{3}$ and the weight of the batteries is too high.

The energy balance for the itinerary Albacete-CartagenaAlbacete is evaluated in terms of fuel cost. The diesel engine needs an average of $4.44 \mathrm{l} / \mathrm{km}$. If the loco performs two travels a day during five workdays ( 45 weeks a year), and we assume the following efficiencies:

- Diesel engine: 37 to $41 \%$

- Main generator: $90 \%$

- Electronic converters: $95 \%$

- Traction motors: $75-80 \%$

- Batteries (storage): $85 \%$

- $\quad$ S-Capacitoris (storage): near $100 \%$

The annual cost fuel of a locomotive in this itinerary $(2 * 250 \mathrm{~km}$ ) ranges from 400 to $480 \mathrm{k} € /$ year (depending on the fuel cost fluctuations). The overall gain of efficiency is closed to $9,5 \%$ (19.2\% from Albacete to Cartagena, but only a $4.7 \%$ in the return itinerary, due to the lower availability to store energy). The results are shown in table V.

Table V. Gains in energy efficiency

\begin{tabular}{|l|c|c|c|c|}
\hline Itinerary & $\begin{array}{c}\text { Energy } \\
\text { (GJ) }\end{array}$ & $\begin{array}{c}\text { Storage } \\
\text { (GJ) }\end{array}$ & $\begin{array}{c}\text { Gains in } \\
\text { efficiency. } \\
\text { SC (\%) }\end{array}$ & $\begin{array}{l}\text { Gains in } \\
\text { efficiency. } \\
\text { Battery (\%) }\end{array}$ \\
\hline $\begin{array}{l}\text { Albacete } \\
\text { to } \\
\text { Cartagena }\end{array}$ & 3.08 & 0.59 & 16.34 & 12.26 \\
\hline $\begin{array}{l}\text { Cartagena } \\
\text { to } \\
\text { Albacete }\end{array}$ & 6.17 & 0.29 & 4.04 & 3.02 \\
\hline
\end{tabular}

This gain in efficiency supposes a reduction in fuel expenses from 75 to $95 \mathrm{k} € /$ year, i.e. a cost effective alternative in the medium term (see table IV) for SC and NiCd batteries storage.

\section{THE IMPROVEMENT OF RAILWAYS GENERATION RESOURCES}

Voltage regulation and power demand are key performance limiting factors in a railway network with supply through overhead lines. The potential use of supercapacitors to improve voltage regulation and efficiency is described in the bibliography (for example subway substations) to demonstrate the potential benefits of utilising energy storage in a railway system. The alternative of electrical locomotive storage is to store energy in railway substations. Electric railway systems can be described as electrical networks, with moving and changing loads. These moving loads pose voltage regulation problems. In this way, trains should be designed to operate within a range of voltages; however the performance of a motor is done by the voltage, and hence significant changes in voltage levels limit the potential and necessary speed of a train. The density of the traffic increases voltage regulation problems. If the voltage falls below a minimum, trains are unable to work with an appropriate technical and energy efficiencies.

At this point, it is necessary to consider that diesel-electric locomotives usually haul coaches and goods wagon under electrified itineraries (for example in our case from Madrid to Albacete, $300 \mathrm{~km}$ ). The locomotive only needs the full power of diesel engine and/or storage reservoir in a limited percent of time (for instance 10\%, see figure 7). From $80 \%$ to $90 \%$ of time the locomotive has a surplus of energy (up to $1.5 \mathrm{MW}$ ) to be supplied to the catenary if we dispose a pantograph in the roof (see figure 13) of the loco to supply energy from main generator to the overhead $3 \mathrm{kV}$-DCcontact lines (for example when other train starts near our loco in the itinerary).

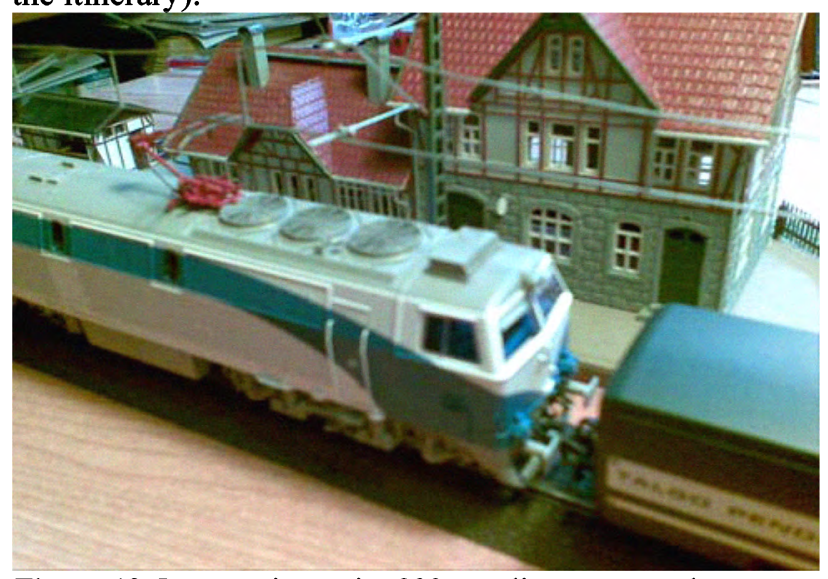

Figure 13. Locomotive series 333 supplies power to the contact line in a train stop (recreation) through the pantograph (roof) to provide energy for an electric unit start.

In this way, we will have some mobile and changing distributed generator (DMG) in the main lines. This topic, may work with excellent results (the control technology is very closed to the one used in distributed or demand response) and will be evaluated in a next paper by authors. 


\section{CONCLUSIONS}

This paper presents an alternative solution for increasing the energy efficiency of a diesel-electric train without impairing on its dynamic characteristics. This solution enhance the lifecycle of these units on secondary itineraries. To reach these goals, two different alternatives have been evaluated: store the energy of the diesel dynamic braking systems and reduce the diesel motor size (from other locomotives). For both solutions, an energy storage system must be added with an appropriate capacity. Super-capacitors and some different technologies of batteries have been chosen for this purpose. Dynamic braking energy can therefore be recuperated and energy efficiency improved with costefficient alternatives. The fuel reduction by $10 \%$ (and pollutants and volatile organic compounds too) is found in comparison to the actual fuel demand..

The present simulations are valid for the itinerary chosen in the example, but the same method can be applied throught the software to any other railway line powered by Altaria or Talgo trains (a standard for Spanish operators in non electrified lines for passenger services).

\section{REFERENCES}

[1] U.S. Department of Energy, 2007, Plug-In Hybrid Electric Vehicle R\&D Plan, Energy Efficiency and Renewable Energy, USA. Available on line http:// www.eere.energy.gov/vehiclesandfuels.

[2] A. Rojas: Flywheel Energy Matrix Systems-Today's Technology, Tomorrow's Energy Storage Solution, Applications Engineering, Beacon Power Corp., Wilmington. http://www.beaconpower.com

[3] S. M. Schoenung, W. V. Hassenzahl, 2007,: Long-vs. Short-Term Energy Storage: Sensitivity Analysis, A Study for the DOE Energy Storage Systems Program, Sandia Report SAND2007-4253, Sandia National Laboratories, California, USA. Available on line http://www.prod.sandia.gov/cgi-bin/techlib/accesscontrol.pl/2007/074253.pdf

[4] E.R.Furlong, M. Piemontesi, P. Prasad, D. Sukumar: Advances in energy storage techniques for critical power systems, General Electric Company, GE Digital Energy, Atlanta. Available on line http:// www.battcon.com/PapersFinal2002/FurlongPaper200 $\underline{2 . p d f}$

[5] R. F. Thelen, J. D. Herbst, M. T. Caprio, 2003,: $A$ 2MW Flywheel for Irbid Locomotive Power, IEEE Vehicular Technology Conference, 2003. VTC 2003Fall.

[6] L. Charlier, 2007, "Le ferroviaire s'intéresse à la motorisation hybride", Rail Passion, ${ }^{\circ} 117$, pp.32-34.

[7] ALSTHOM-RENFE: Service and Operating Manualof the Diesel Electric Locomotive Class 333.300.

[8] GEC-ALSTHOM, RENFE, 2002,: Operating Manual of the Diesel-Electric Locomotive GE series $J 26 \mathrm{CW}$ SS, Class 319.401 to 410.
[9] R. Kaller, J. M. Allenbach, 1995, Traction électrique, 1995, Presses Polytechniques et Universitaires Romandes, Lausanne, Switzerland.

[10] W.H. Hay, 1985, Railroad Engineering ( $2^{\text {nd }}$ edition), John Wiley and Sons, New York, USA.

[11] P. Barrade, B. Destraz, A. Rufer, 2004, Hybrid vehicle in railways applications: supercapacitive energy storage for diesel-electric locomotives, Laboratory of Industrial Electronics, Swiss Federal Institute of Technology, Lausanne.

\section{Acknowledgments}

This work was supported by the Spanish Government (Ministerio de Ciencia e Innovación) under Research Project ENE2007-67771-C02-02/CON.

The authors are very grateful to the information, data and timetables supplied by ADIF (Administrador de Infraestructuras Ferroviarias, Spanish Railway Network Operator). 